\title{
Atomic Resolution of Lithium Ions in $\mathrm{LiCoO}_{2}$
}

Yang Shao-Horn ${ }^{1,2}$, Laurence Croguennec ${ }^{2}$, Claude Delmas $^{2}$, Chris Nelson $^{3} \&$ Michael A. O’Keefe ${ }^{3}$

${ }^{1}$ Department of Mechanical Engineering

Massachusetts Institute of Technology

77 Massachusetts Ave., Cambridge, Massachusetts 02139, USA

2 Institut de Chimie de la Matière Condensée de Bordeaux-CNRS

Ecole Nationale Supérieure de Chimie et Physique de Bordeaux

Université Bordeaux I

87 av. Dr A. Schweitzer, 33608 Pessac cedex, France

${ }^{3}$ Materials Sciences Division

Lawrence Berkeley National Laboratory,

1 Cyclotron Road, Berkeley, California 94720, USA.

DISCLAIMER

This document was prepared as an account of work sponsored by the United

States Government. While this document is believed to contain correct

information, neither the United States Government nor any agency thereof, nor

The Regents of the University of California, nor any of their employees, makes

any warranty, express or implied, or assumes any legal responsibility for the accuracy, completeness, or usefulness of any information, apparatus, product, or process disclosed, or represents that its use would not infringe privately owned rights. Reference herein to any specific commercial product, process, or service by its trade name, trademark, manufacturer, or otherwise, does not necessarily constitute or imply its endorsement, recommendation, or favoring by the United States Government or any agency thereof, or The Regents of the University of California. The views and opinions of authors expressed herein do not necessarily state or reflect those of the United States Government or any agency thereof, or The Regents of the University of California.

Ernest Orlando Lawrence Berkeley National Laboratory is an equal opportunity employer. 


\title{
Atomic Resolution of Lithium Ions in $\mathrm{LiCoO}_{2}$
}

\author{
Yang Shao-Horn ${ }^{1,2, *}$, Laurence Croguennec ${ }^{2}$, Claude Delmas ${ }^{2}$, \\ Chris Nelson ${ }^{3}$ and Michael A. O' Keefe ${ }^{3}$
}

${ }^{1}$ Department of Mechanical Engineering, Massachusetts Institute of Technology

77 Massachusetts Ave., Cambridge, Massachusetts 02139, USA

${ }^{2}$ Institut de Chimie de la Matière Condensée de Bordeaux-CNRS and Ecole Nationale Supérieure de Chimie et Physique de Bordeaux Université Bordeaux I

87 av. Dr A. Schweitzer, 33608 Pessac cedex France
${ }^{3}$ Materials Sciences Division, Lawrence Berkeley National Laboratory, 1 Cyclotron Road, Berkeley, California 94720, USA.

*Correspondence should be addressed to YSH.

Submitted to Nature Materials

March 18, 2002 


\title{
Atomic Resolution of Lithium Ions in $\mathrm{LiCoO}_{2}$
}

\author{
Yang Shao-Horn, Laurence Croguennec, Claude Delmas, \\ Chris Nelson and Michael A. O’Keefe
}

\begin{abstract}
$\mathrm{LiCoO}_{2}$ is the most common lithium storage material for lithium rechargeable batteries used widely to power portable electronic devices such as laptop computers. Lithium arrangements in the $\mathrm{CoO}_{2}$ framework have a profound effect on the structural stability and electrochemical properties of $\mathrm{Li}_{\mathrm{x}} \mathrm{CoO}_{2}(0<\mathrm{x}<1)$, however, probing lithium ions has been difficult using traditional X-ray and neutron diffraction techniques. Here we have succeeded in simultaneously resolving columns of cobalt, oxygen, and lithium atoms in layered $\mathrm{LiCoO}_{2}$ battery material using experimental focal series of $\mathrm{LiCoO}_{2}$ images obtained at sub-Ångstrom resolution in a mid-voltage transmission electron microscope. Lithium atoms are the smallest and lightest metal atoms, and scatter electrons only very weakly. We believe our observations of lithium to be the first by electron microscopy, and that they show promise to direct visualization of the ordering of lithium and vacancy in $\mathrm{Li}_{\mathrm{x}} \mathrm{CoO}_{2}$.
\end{abstract}

KEYWORDS: lithium battery, sub-Ångstrom, atomic-resolution, HREM, focal-series reconstruction 


\section{INTRODUCTION}

The mechanism of lithium rechargeable battery operation is based on reversible lithium insertion and extraction processes into and from host structures of negative electrode (for example, graphite) and positive electrode (such as lithium transition metal oxides) materials. Lithium removal from layered $\mathrm{LiCoO}_{2}$ has been studied extensively over the last twenty years ${ }^{1-3}$. Although X-ray and neutron powder diffraction analyses have been able to successfully probe and monitor changes in the cobalt and oxygen positions of $\mathrm{Li}_{\mathrm{x}} \mathrm{CoO}_{2}(0<\mathrm{x} \leq 1)$, they are insensitive to lithium ion arrangements. Lithium and vacancy ordering in $\mathrm{Li}_{\mathrm{x}} \mathrm{CoO}_{2}{ }^{3-5}$ has a profound effect on the structural stability of $\mathrm{CoO}_{2}$ host structure and lithium battery performance. Interactions of an electron beam and atoms of $\mathrm{LiCoO}_{2}$ can be used to image columns of cobalt, oxygen and lithium and potentially to visualize ordering of lithium and vacancy in $\mathrm{Li}_{\mathrm{x}} \mathrm{CoO}_{2}(0<\mathrm{x}<1)$ by high-resolution transmission electron microscope (HRTEM) imaging and simulation.

In the transmission electron microscope (TEM) a beam of electrons passes through the $\mathrm{LiCoO}_{2}$ lattice and scatters from the three-dimensional potential field produced by the arrangement of cobalt, oxygen, lithium nuclei and their electron clouds. The results of the electrons' interaction with the $\mathrm{LiCoO}_{2}$ lattice are encoded on the emergent electron wave as changes in the phase (and, to a lesser extent, the amplitude) of the original incident electron wave. The phase of this exit-surface wave (ESW) is a function of the $\mathrm{LiCoO}_{2}$ potential projected in the direction of the incident electron beam. In the HRTEM, the ESW phase is imaged with an objective lens that imposes additional phase changes due to aberrations such as defect of focus (defocus) and spherical aberration. These phase changes limit the resolution of mid-voltage HRTEMs to $1.6 \AA$ (native resolution) ${ }^{6}$. Although cobalt atoms can be easily imaged at 
resolutions above $1.6 \AA$, better resolution is required to "see" lighter atoms such as oxygen and lithium. Recent advances in HRTEMs have moved beyond the native TEM resolution to the information limit $^{7}$ of the TEM, by focal-series reconstruction (FSR) of the ESW from a series of images obtained over a range of defocus values ${ }^{8}$. This method has achieved resolution of carbon and nitrogen atoms in diamond ${ }^{9}$ and $\mathrm{GaN}^{10}$, respectively. In this study, we have applied this approach to examine a $\mathrm{LiCoO}_{2}$ powder sample and we here report, for the first time, atomic resolution of lithium ions in $\mathrm{LiCoO}_{2}$.

\section{RESULTS AND DISCUSSIONS}

X-ray powder diffraction analyses showed that the $\mathrm{LiCoO}_{2}$ sample used in this study could be indexed to an hexagonal cell with $S . G . \mathrm{R} \overline{3} \mathrm{~m}$ and lattice parameters of $\boldsymbol{a}=\boldsymbol{b}=2.8138 \AA$ and $c=14.0516 \AA$, which is consistent with previous studies ${ }^{1,2,11,12}$. The $\mathrm{LiCoO}_{2}$ structure consists of $\mathrm{CoO}_{2}$ slabs with layers of lithium in-between the slabs, as shown in Fig. 1a, where lithium is believed to be fully ionized ${ }^{13}$. Columns of lithium ions in this structure can be seen clearly in the [110] projection, as shown in a two-dimensional cell of $2.44 \AA$ by $14.05 \AA$ in Fig. 1b. This cell, with a thickness in the electron beam direction of $2.8138 \AA$, is used as a repeatable unit in the simulated HRTEM images.

In order to estimate the resolution required to resolve lithium ions, we first computed a series of images from the $\mathrm{LiCoO}_{2}$ structure along the [110] direction using the weak-phase object approximation over the resolution range $2 \AA$ to $0.6 \AA$. As shown in Fig. 2 , the series showed that cobalt atoms would be visible at $2 \AA$ resolution and that oxygen atoms would appear at $1.4 \AA$ resolution. The lithium ions would be visible at $1.0 \AA$ A resolution, and would become clear at 0.8 
$\AA$, where all three atom types could be clearly distinguished. As the weak-phase object approximation can be only applied to extremely thin specimen (typically less than $10 \AA$ ), the phase of the specimen ESW was computed for resolutions from $0.8 \AA$ to $1.2 \AA$ as a function of specimen thickness from 2 to 40 cells ( $6 \AA$ to $113 \AA$ ) along the [110] zone axis (in the incident beam direction). Results varied only slightly for resolutions from $0.8 \AA$ to $1.0 \AA$. For a very thin specimen, the phase of the ESW is proportional to the projected potential; for example, the phase peaks in $\mathrm{LiCoO}_{2}$ are strongest at the cobalt atom position for specimens thinner than eight unit cells (Fig. 3). For thicker specimens, the heights of the phase peaks at the atom column positions oscillate with specimen thickness at rates that depend on the scattering power of the atoms making up the atom column; the oxygen peak is stronger than the Co peak in the thickness range from 8 to 18 unit cells (Fig. 3). In the range from 15 to 18 unit cells, all the atom peaks are white, with bright oxygen atoms arranged around rows of "fuzzy" cobalt atoms and weak lithium atoms (Fig. 3).

The ESW phase image reconstructed from experimental images of a thin edge of a $\mathrm{LiCoO}_{2}$ crystal along the [110] zone axis shows all three types of atoms in $\mathrm{LiCoO}_{2}$ (Fig. 4a). Comparison with a simulated ESW phase image based on a crystal model of 17 unit cells thick (48 $\AA$ ) at $0.9 \AA$ resolution (Fig. 4b), reveals that all the atom peaks have the characteristics predicted by the simulations and clearly show the positions of all the atom columns over an area of several unit cells. The O-Co-O units can clearly be distinguished, with each fuzzy cobalt peak flanked by a pair of bright oxygen atoms, and the weak spots lying between them can be identified as the electron scattering intensities of the lithium ions (arrowed in both Figs 4a and 4b). It is clear that the oxygen atoms lie closer to the cobalt than to the lithium in Fig. 4, just as in the simulated ESWs (Fig. 3), providing additional confirmation for our identification of these 
atom columns. This result is further supported by the fact that ESW phase images simulated from a $\mathrm{CoO}_{2}$ model (a model with the lithium ions removed from the $\mathrm{LiCoO}_{2}$ layered structure) show no sign of intensities at the lithium positions; the weak white spots present in the experimental reconstruction at the lithium positions appear in the simulation only when the model has the lithium atoms present.

Accurate reconstruction of the phase of the specimen ESW produces an "in focus" image showing the phase peaks from the atom columns. However, if reconstruction is inadvertently to a plane displaced from the exit surface, the result will be out of focus and the peaks will blur and spread to produce a result with mixed and overlapped peaks. In reconstructing $\mathrm{LiCoO}_{2} \mathrm{ESWs}$, we found that only small areas of the specimen could be brought to an in-focus condition at any one choice of an exit-surface plane. This is consistent with the hypothesis that the thin edge of the $\mathrm{LiCoO}_{2}$ crystal in Fig. 4 was fractured, so that the surface is approximately planar (to 10-20 $\AA$ ) over an extent of only a few unit cells.

Although atomic resolution of lithium columns in $\mathrm{LiCoO}_{2}$ has been achieved in this work, experimental HRTEM imaging of lithium and vacancy arrangements in $\mathrm{Li}_{\mathrm{x}} \mathrm{CoO}_{2}$ samples is difficult. A major limitation resides in the fact that $\mathrm{Li}_{\mathrm{x}} \mathrm{CoO}_{2}$ samples become unstable under the field emission electron beam due to intrinsically poor thermal stability ${ }^{14}$. Observations of carbon atoms in diamond suggest that a microscope with an $\mathrm{LaB}_{6}$ electron emitter can produce less severe specimen beam damage and specimen heating than one with a field emission electron beam ${ }^{15}$. Very high voltage is required to reach sub-Ångstrom resolution with $\mathrm{LaB}_{6}$, but a possible alternative to our method would be to image lithium and vacancy arrangements in $\mathrm{Li}_{\mathrm{x}} \mathrm{CoO}_{2}$ specimens using an $\mathrm{LaB}_{6}$ microscope at an energy greater than $1 \mathrm{MeV}$. 


\section{METHODS}

The stoichiometric $\mathrm{LiCoO}_{2}$ powder sample used for HRTEM studies was synthesized from a heat-treatment of a stoichiometric mixture of $\mathrm{Li}_{2} \mathrm{CO}_{3}$ and $\mathrm{Co}_{3} \mathrm{O}_{4}$ at $600^{\circ} \mathrm{C}$ under $\mathrm{O}_{2}$ for $12 \mathrm{~h}$, followed by two subsequent heat-treatments at $900^{\circ} \mathrm{C}$ under $\mathrm{O}_{2}$ for $24 \mathrm{~h}$ and $12 \mathrm{~h}$. The phase purity of this sample was confirmed by X-ray powder diffraction on an INEL CPS 120 diffractometer with an area detector and $\mathrm{CoK}_{\alpha 1}$ radiation. The lattice parameters of the layered $\mathrm{LiCoO}_{2}$ were refined by profile matching using FullProf computing program ${ }^{16}$. The powder sample was ground by agate mortar and pestle, suspended in ethanol and deposited on copper grids with holy carbon network for HRTEM analysis. The One-Ångstrom Microscope (OÅM) in the National Center for Electron Microscopy at Lawrence Berkeley National Laboratory was used. This microscope combines a modified field-emission TEM CM300FEG/UT with the Philips/Brite-Euram software for focal-series reconstruction by Coene and Thust ${ }^{17,18}$, and can achieve a resolution of $0.78 \AA^{19}$. The $\mathrm{O} \AA \mathrm{M}$ was operated at $300 \mathrm{keV}$ and several focal series of images collected from the $\mathrm{LiCoO}_{2}$ powder sample in the [110] orientation. The recording of focal image series was started at a nominal defocus of $-3300 \AA$ and stepped back towards focus in increments of $24 \AA$. Under proper conditions, the series can contain information to the information limit of the microscope. The exact defocus of each image in the focal series of twenty was measured, and the images were then used as input to the reconstruction software ${ }^{17,18}$ to obtain estimates of the phase of the $\mathrm{ESW}$ of $\mathrm{LiCoO}_{2}$.

Simulations of electron microscope images can be routinely computed from model structures $^{20}$. For very thin specimens imaged at "optimum defocus", images can be simple projections of the specimen potential to a given resolution ${ }^{7}$. A series of simulations of such "weak phase objects" reveals the best image that can be expected at any given resolution (Fig. 2). 
As specimen thickness is increased, images diverge from simple projections, due to the increasing proportion of dynamic scattering contributing to the electron wave at the specimen exit surface. We used the Cowley-Moodie multislice description of dynamic electron scattering ${ }^{21}$ to compute ESWs from $\mathrm{LiCoO}_{2}$ model structures over a range of specimen thickness for a number of different resolutions. The rapid departure from the thin-crystal result is evident (Fig. 3). We compared the phases of simulated ESWs with the phases of experimentally-reconstructed ESWs because the phase of the scattered electron beam carries the two-dimensional information on the spatial variation of the specimen potential distribution when it is projected to the specimen exit surface ${ }^{7}$.

\section{ACKNOWLEDGMENTS}

This work was supported by National Science Foundation International Research Fellow Award INT-0000429 and the Director, Office of Science, Office of Basic Energy Sciences, Material Sciences Division, of the U.S. Department of Energy, under contract No. DE-AC03$76 \mathrm{SF} 00098$. 


\section{FIGURE CAPTIONS}

Fig. 1. a: Layered $\mathrm{LiCoO}_{2}$ structure with $S . G . \mathrm{R} \overline{3} \mathrm{~m}$ drawn with lithium ions horizontally between $\mathrm{CoO}_{2}$ octahedra. b: Projection in the [110] zone axis shows lithium, cobalt and oxygen columns. The projected cell is $2.44 \AA$ (angstrom) by $14.05 \AA$.

Fig. 2. Images of $\mathrm{LiCoO}_{2}$ in the [110] zone axis simulated under thin-crystal ("weak-phaseobject") conditions for increasing resolution (marked) show that horizontal rows of atoms of cobalt should be resolvable at $2 \AA$ (angstrom), oxygen at $1.4 \AA$, and lithium at $1 \AA$.

Fig. 3. Simulated $\mathrm{LiCoO}_{2}$ ESW-phase images in the [110] zone axis at $0.9 \AA$ (angstrom) resolution for increasing specimen thickness (marked in unit cells of $2.814 \AA$ ) show horizontal rows of phase peaks at atom positions. Oxygen rows are closer (2.05 ̊ apart) when spanning Co positions and wider $(2.63 \AA)$ around Li positions.

Fig. 4. a: $\mathrm{LiCoO}_{2} \mathrm{ESW}$-phase image, reconstructed from 20 experimental images, shows lithium ions in rows (arrowed) between O-Co-O groups. b: Insert ESW-phase simulation for $48 \AA$ (angstrom) thickness and 0.9 Å resolution. 


\section{REFERENCES}

1. Mizushima, K., Jones, P. C., Wiseman, P. J. \& Goodenough, J. B. $\operatorname{Li}_{\mathrm{x}} \mathrm{CoO}_{2}(0<\mathrm{x} \leq 1)$ : a new cathode material for batteries of high energy density. Materials Research Bulletin 15, 783-789 (1980).

2. Ohzuku, T. \& Ueda, A. Solid-state redox reactions of $\mathrm{LiCoO}_{2}(\mathrm{R}-3 \mathrm{~m})$ for 4 volt secondary lithium cells. J. Electrochem. Soc. 141, 2972-2977 (1994).

3. Reimers, J. N. \& Dahn, J. R. Electrochemical and in situ X-ray diffraction studies of lithium intercalation in $\mathrm{Li}_{\mathrm{x}} \mathrm{CoO}_{2}$. J. Electrochem. Soc. 139, 2091-2097 (1992).

4. Shao-Horn, Y., Levasseur, S., Weill, F. \& Delmas, C. Probing lithium and vacancies ordering in $\mathrm{Li}_{\mathrm{x}} \mathrm{CoO}_{2}(\mathrm{x} \approx 0.5)$ : An electron diffraction study. J. Electrochem. Soc. 150 , A366-A373 (2003).

5. Van der Ven, A., Aydinol, M. K. \& Ceder, G. First-principles evidence for stage ordering in $\mathrm{Li}_{\mathrm{x}} \mathrm{CoO}_{2}$. J. Electrochem. Soc. 145, 2149-2155 (1998).

6. Scherzer, O. The theoretical resolution limit of the electron microscope. Journal of Applied Physics 20, 20-29 (1949).

7. O'Keefe, M. A. Resolution in high-resolution electron microscopy. Ultramicroscopy 47, 282-297 (1992).

8. $\quad$ Schiske, P. in Image Processing And Computer-Aided Design (ed. Hawkes, P. W.) 82-90 (Acad. Press, London, 1973).

9. O'Keefe, M. A. et al. Sub-Ångstrom high-resolution transmission electron microscopy at 300keV. Ultramicroscopy 89, 215-241 (2001).

10. Kisielowski, C., Hetherington, C. J. D., Wang, Y. C., Kilaas, R., O'Keefe, M. A. \& Thust, A. Imaging columns of the light elements carbon, nitrogen and oxygen at sub-Ångstrom resolution. Ultramicroscopy 89, 243-263 (2001).

11. Levasseur, S., Menetrier, M., Suard, E. \& Delmas, C. Evidence for structural defects in non-stoichiometric HT- $\mathrm{LiCoO}_{2}$ : electrochemical, electronic properties and ${ }^{7} \mathrm{LiNMR}$ studies. Solid State Ionics 128, 11-24 (2000).

12. Amatucci, G. G., Tarascon, J. M. \& Klein, L. C. $\mathrm{CoO}_{2}$, the end member of the $\mathrm{Li}_{\mathrm{x}} \mathrm{CoO}_{2}$ solid solution. J. Electrochem. Soc. 143, 1114-1123 (1996).

13. Ceder, G., Aydinol, M. K. \& Kohan, A. F. Application of first-principles calculations to the design of rechargeable Li-batteries. Comp. Mat. Sci. 8, 161-169 (1997).

14. Dahn, J. R., Fuller, E. W., Obrovac, M. \& Von Sacken, U. Thermal stability of $\mathrm{Li}_{\mathrm{x}} \mathrm{CoO}_{2}$, $\mathrm{Li}_{\mathrm{x}} \mathrm{NiO}_{2}$ and lambda- $\mathrm{MnO}_{2}$ and consequences for the safety of Li-ion cells. Solid State Ionics 69, 265-270 (1994). 
15. Zhang, Y., Ichinose, H., Ishida, Y., Ito, K. \& Nakanose, M. Atomic and electonics structures of grain boundary in chemical vapor deposited diamond thin films. Material Science Forum 204, 207 (1996).

16. Rodriguez-Carvajal, J. Recent advances in magnetic structure determination by neutron powder diffraction. Physica B 192, 55-69 (1993).

17. Thust, A., Coene, W. M. J., Op de Beeck, M. \& Van Dyck, D. Focal-series reconstruction in HRTEM: simulation studies on non-periodic objects. Ultramicroscopy 64, 211-230 (1996).

18. Coene, W. M. J., Thust, A., Op de Beeck, M. \& Van Dyck, D. Maximum-likehood method for focus-variation image reconstruction in high resolution transmission electron microscopy. Ultramicroscopy 64, 109-135 (1996).

19. O'Keefe, M. A., Nelson, E. C., Wang, Y. C. \& Thust, A. Sub-Ångstrom resolution of

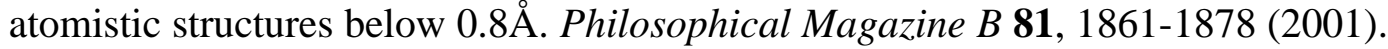

20. O'Keefe, M. A., Buseck, P. R. \& Iijima, S. Computed crystal structure images for high resolution electron microscopy. Nature 274, 322-324 (1978).

21. Cowley, J. M. \& Moodie, A. F. The scattering of electrons by atoms and crystals. I. A new theoretical approach. Acta Cryst. 10, 609-623 (1957). 


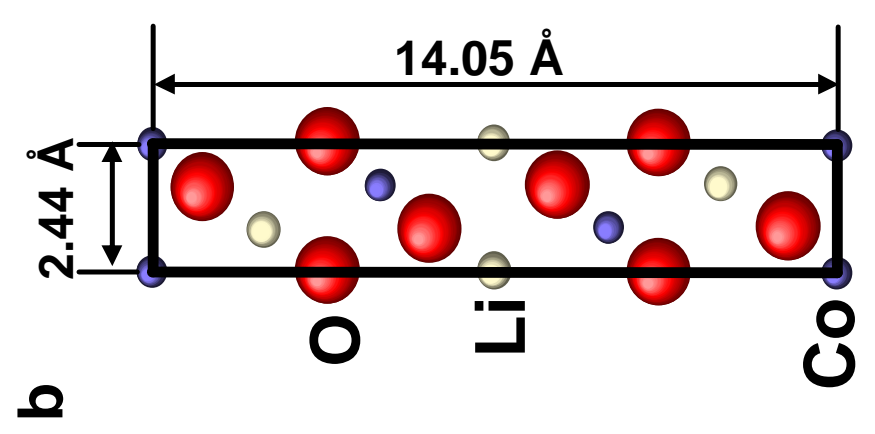

혼

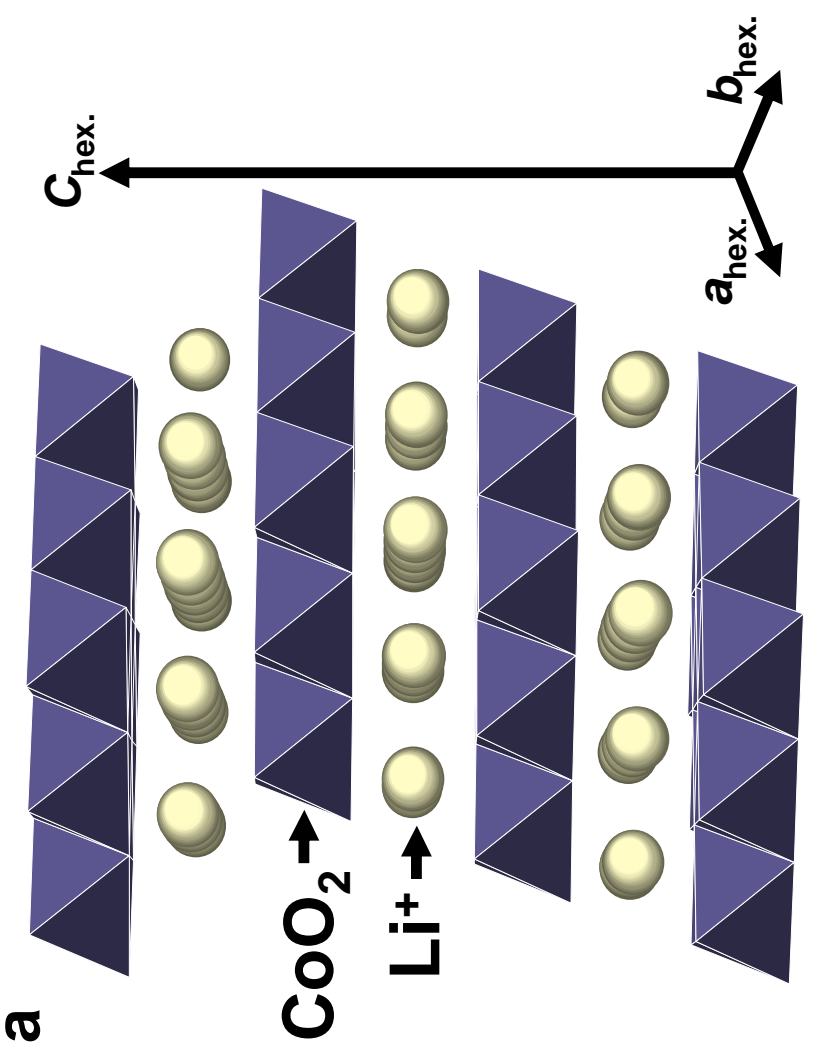

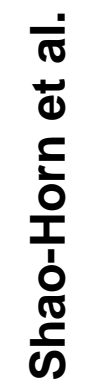


인

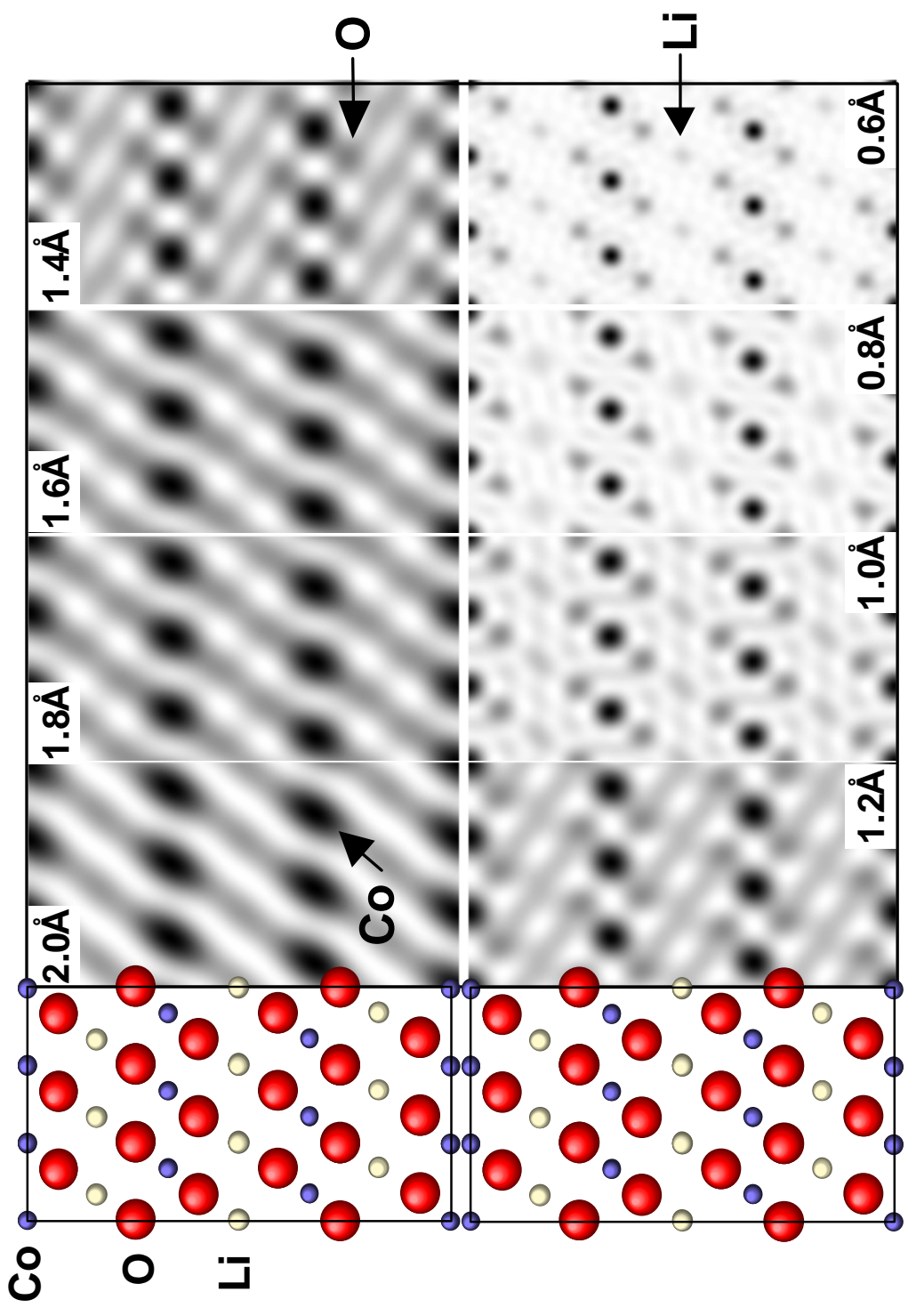

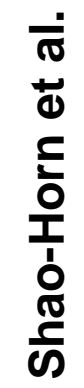




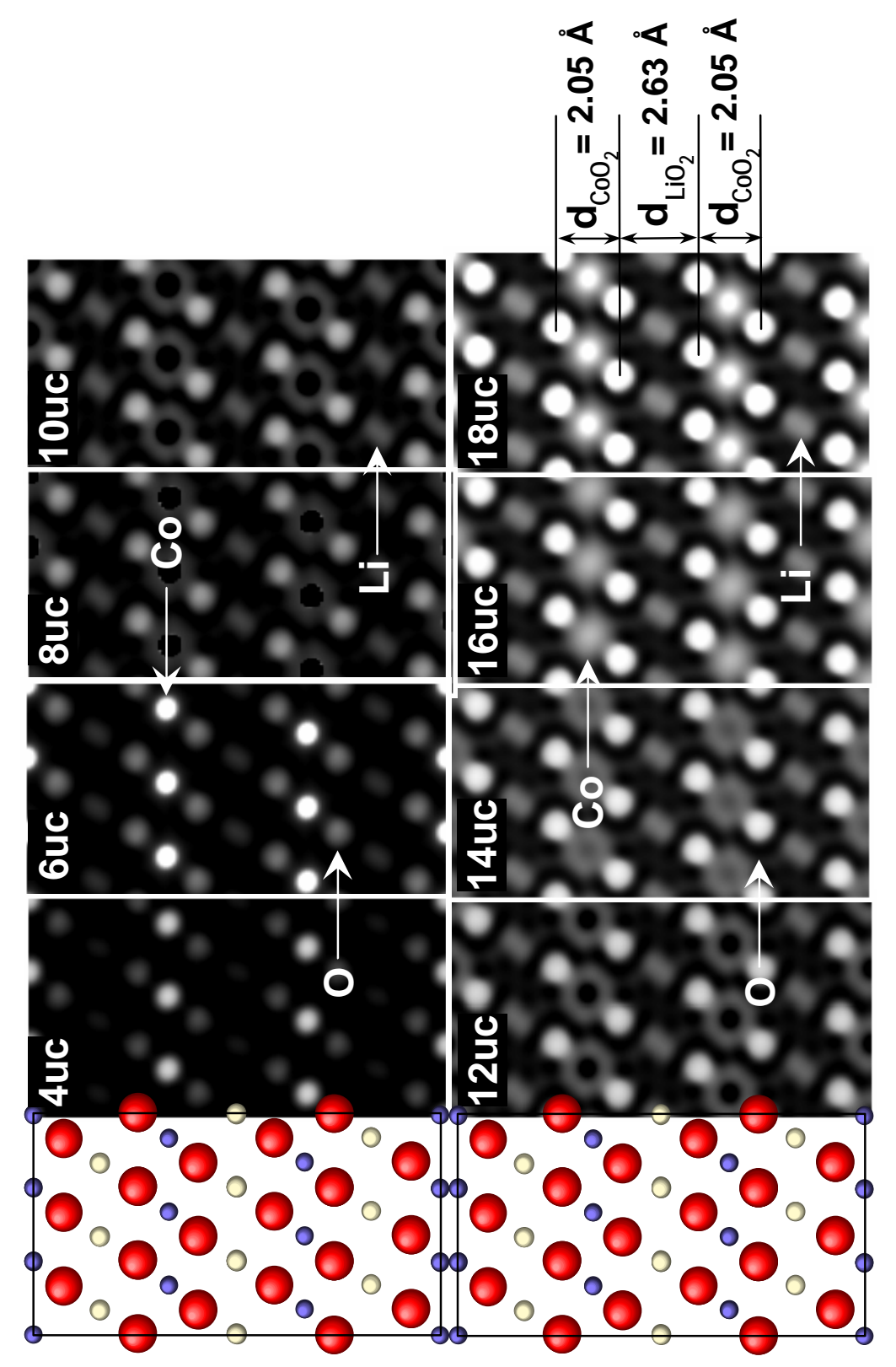

0
논
미

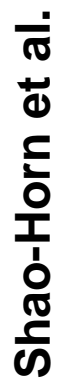


+
0
은

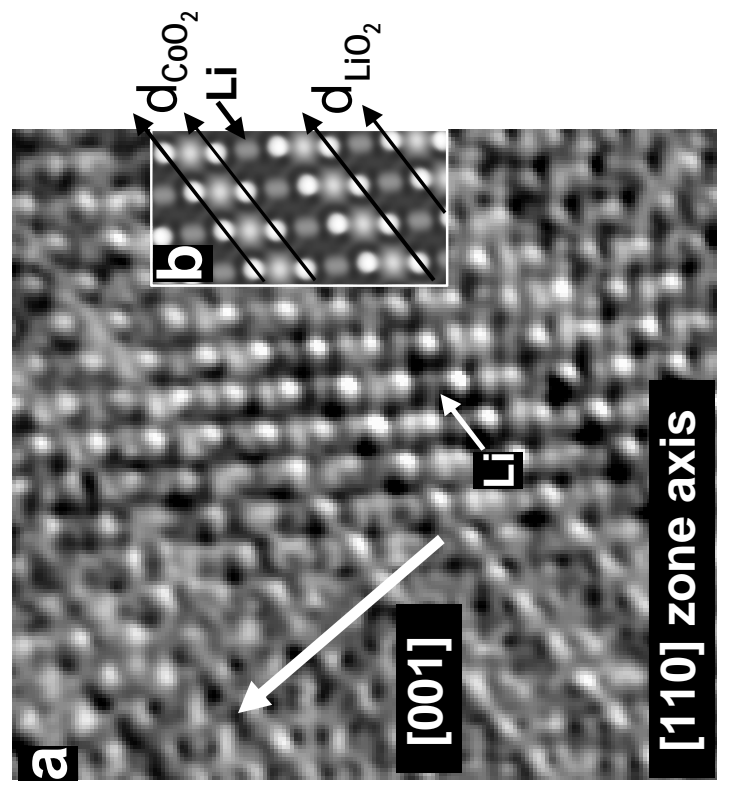

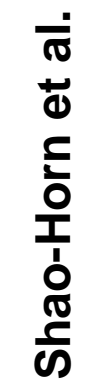

